Check for updates

The BMJ

Cite this as: BMJ 2021;375:n2696 http://dx.doi.org/10.1136/bmj.n2696 Published: 05 November 2021

\section{Healthcare and tech companies pledge to decarbonise NHS supply chain by 2045}

\section{Zosia Kmietowicz}

A group of influential global healthcare and tech companies has pledged to decarbonise the NHS supply chain by 2045 at the latest, supporting the ambition of the NHS in England to become the world's first net zero health service.

The International Leadership Group for a Net Zero NHS, led by David Prior, current chairman of NHS England, brings together the chief executive officers of major suppliers to the NHS, as well as key trade bodies, The BMJ, the independent charity the Health Foundation, and EAT, the non-profit, science based global platform for food system transformation.

The group has written an open letter in The BMJ to the 80 ooo global suppliers that make up the NHS supply chain, urging them to act now and commit to work with the NHS to decarbonise their operations by 2045 at the latest. ${ }^{1}$

The NHS has committed to reach net zero carbon by 2040 for its own emissions, but nearly two thirds of its carbon footprint resides in its global supply chain.

"We understand that taking action on this agenda is complex, not least because our supply chains are global. It will require strong leadership, bold commitments, and a clear roadmap with intermediate targets. But it is critical if we are to support a healthier planet and healthier people," says the letter.

In recognition of the urgency of the threat posed by climate change and its own role in securing a healthier world, the BMJ Publishing Group has pledged to achieve net zero by 2040 . This means making changes to cut carbon emissions to the lowest amount possible and offsetting the remainder.

Fiona Godlee, editor in chief of The BMJ and independent member of the International Leadership Group for a Net Zero NHS, said, "BMJ recognises the urgency with which we have to tackle climate change for healthier people and a healthier planet, now and in the future. We fully support the NHS in its roadmap to achieving net zero, including its work with suppliers to decarbonise.”

She added, "The BMJ has extensively covered climate change in the past, raising awareness of its impacts and the role of the medical and wider health professions in reducing demand for healthcare, decarbonising health systems, advocating for societal change, and being role models for individual behaviour change.

"To build on this, we are committing to net zero publishing by 2040 and we will publish additional regular educational content to guide clinicians and researchers on what they can do to tackle climate change."
Chris Jones, chief executive officer of BMJ, said, "BMJ's vision of a healthier world is the goal to which all our efforts are directed, and we know this will never be realised unless urgent action is taken to defeat the climate threat."

\section{Signatories to the open letter}

\section{Suppliers}

- Alan Jope, chief executive officer, Unilever

- Alex Gorsky, chairman of the board and chief executive officer, Johnson \& Johnson

- Emma Walmsley, chief executive officer, GSK

- Geoff Martha, chairman and chief executive officer, Medtronic

- Lars Fruergaard Jørgensen, president and chief executive officer, Novo Nordisk Global

- Lisa Jackson, vice president, environment, policy and social initiatives, Apple

- Michel Vounatsos, chief executive officer, Biogen

- Pascal Soriot, chief executive officer, AstraZeneca

- Philip Jansen, chief executive officer, BT Group

- Roland Diggelmann, chief executive officer, Smith+Nephew

- Satya Nadella, chief executive officer, Microsoft

- Xavier Martiré, chairman of the management board and chief executive officer, Elis

\section{Trade bodies}

- Michelle McMurry-Heath, chief executive officer, Biotechnology Innovation Organization

- Peter Ellingworth, chief executive officer, Association of British HealthTech Industries

- Richard Torbett, chief executive officer, Association of the British Pharmaceutical Industry

\section{Independent members}

- Fiona Godlee, editor in chief, The BMJ

- Gunhild Stordalen, founder and executive chair, EAT

- Jennifer Dixon, chief executive, the Health Foundation

A commitment to decarbonise by 2045: an open letter to all NHS suppliers [electronic response to Dobson ], et al. Accelerating climate action: the role of health professionals]. BMJ [2021]. www.bmj.com/content/375/bmi.n2425/rr-4. 